\title{
A EDICIÓN SINÓPTICA E A SÚA APLICACIÓN AO ESTUDO DA VARIACIÓN LINGÜÍSTICA NA LÍRICA GALEGO-PORTUGUESA
}

Helena Bermúdez Sabel

Universidade de Santiago de Compostela doi:10.17075/tucmeg.2015.006 



\section{INTRODUCIÓN ${ }^{42}$}

Toda aproximación a un cancioneiro debería incluír a historia do manuscrito desde que este foi confeccionado até o momento presente, unha descrición material, a indicación do seu contido, a análise da constitución interna da colectánea -a escolla de autores e pezas-, un exame paleográfico rigoroso e, finalmente, o estudo das súas particularidades lingüísticas. Precisamente, son estes dous últimos aspectos os que adoitan ser abordados dunha maneira máis superficial (Zufferey 1987: 2) e é neste campo en que os estudos da lírica profana galego-portuguesa presentan maiores lacunas.

Concretamente, para a tradición manuscrita da lírica profana galegoportuguesa percíbese unha alarmante asimetría nos aspectos que vimos de nomear. ${ }^{43}$ Limitándonos aos tres grandes relatores. Do Cancioneiro da Ajuda (A) contamos con estudos da súa historia material moi completos (véxanse, Ramos 1993, 1994, 2009; Arbor Aldea 2004, 2008, 2009). Do Cancioneiro da Biblioteca Nacional (B), o testemuño que máis textos transmite, apenas podemos citar a descrición que Anna Ferrari elabora antes da restauración do manuscrito (Ferrari 1979) e a entrada que a mesma autora (Ferrari 1993a) redacta para o Dicionário da Literatura Medieval Galega e Portuguesa (Lanciani/Tavani 1993). Por último, a única descrición material do Cancioneiro da Biblioteca Vaticana $(V)$ da que dispón a crítica é o estudo realizado pola propia Ferrari, tamén como entrada do citado Dicionário da Literatura Medieval Galega e Portuguesa (Ferrari 1993b).

Esta asimetría patente nos estudos que versan sobre a descrición material agrávase ao procurarmos contributos de corte lingüístico, xa que en ningún momento se analizou a lingua desta tradición poética, coa excepción dalgunha achega que limita a súa análise, fundamentalmente, a determinados elementos gráficos do Cancioneiro de Ajuda (véxanse como exemplos Arbor/Varela 2008, Mariño/Varela 2005, Ramos 1994, Rodríguez/Varela 2007, Varela 2005, e

\footnotetext{
${ }^{42}$ Este traballo foi realizado no marco do Programa de Formación del Profesorado Universitario (AP2012 4518) do Ministerio de Educación Cultura y Deporte.

${ }^{43}$ A propósito dos testemuños que envían a lírica profana galego-portuguesa, que citaremos ao longo deste traballo, vid. Gonçalves (1993).
} 
algún estudo mais amplo como Souto 2008) xunto con análises de fenómenos lingüísticos particulares (vid. Ferreiro 2008a, 2008b; Ramos 1988, 2005, 2011). Esta importante carencia implica grandes límites, por exemplo, á hora de abordar a edición crítica dos textos.

\section{A EDICIÓN SINÓPTICA EXPERIMENTAL}

Para enfocar a análise lingüística dunha tradición manuscrita, o estudo do fenómeno da variación preséntase como un elemento chave que permite unha mellor caracterización desde o punto de vista da lingua dos distintos testemuños, pois, precisamente, ao acoutar a análise aos aspectos que varían dun manuscrito a outro estamos identificando o que teñen de particular.

Partindo desta premisa, consideramos a edición sinóptica experimental como un eficaz punto de partida para unha análise lingüística. Como se sabe, a edición sinóptica consiste na reprodución simultánea, en páxinas ou columnas confrontadas, das transcricións diplomáticas de cada un dos testemuños da obra obxecto de análise (Roudil 1986: 84; Pérez Priego 1997: 44). Esta superposición de signo con signo cunha finalidade comparativa xustifica a denominación de «sinóptica»; o adxectivo «experimental» débese ao amplo abano de posibilidades de análise que permite este tipo de edición (Sánchez-Prieto Borja 1998: 35).

Unha edición sinóptica experimental ten a vantaxe de respectar a «personalidade» de cada testemuño da tradición textual por complexa que esta for. En palabras de Jean Roudil: «il convient de respecter la personnalité de chacune des versions d'une tradition textuelle - (la personnalité ne se divise pas, c'est donc bien une intégralité qu'il faut préserver à côté d'autres personnalités) —, et de raconnaître le droit à l'individualité d'une version» (1986: 81). A diferenza doutros tipos de edición, a sinóptica experimental non ofrece unha proposta de lectura crítica final nin asume a superioridade ou preeminencia duns manuscritos sobre outros, polo que mesmo os descripti, prescindíbeis nunha edición crítica na súa fase de constitutio textus, teñen validade nunha edición deste tipo, xa que a súa inclusión permite realizar estudos máis completos sobre a lingua e as grafías dos testemuños. Así pois, a edición sinóptica experimental preséntase como unha ferramenta que desdobra o contido lingüístico do texto no proceso da súa transmisión, converténdoa nunha metodoloxía que «es válida aunque sea incongruente con los métodos y objetivos "normales" de una edición crítica» (Orduna 2005: 154). 


\section{A EDICIÓN SINÓPTICA APLICADA Á LÍRICA PROFANA GALEGO-PORTUGUESA}

A xustificación teórica e o desenvolvemento metodolóxico da edición sinóptica débese ao xa mencionado Jean Roudil, filólogo francés que aplica esta novidosa metodoloxía á edición dos textos xurídicos de Jacobo de Junta (Roudil 1986).

A brevidade destes e as características intrínsecas á súa transmisión, é dicir, o facto de estaren sempre ligados á codificación escrita, son factores que xustifican o uso desta tipoloxía ecdótica. Tampouco se debe obviar que, debido ao carácter xurídico dos testemuños editados por Roudil, as variantes de redacción teñen unhas causas e unhas consecuencias moi particulares, polo que a procura da reconstrución dun texto orixinal perde a súa relevancia. Estes elementos materiais e a propia modalidade dos textos estudados condicionan o modelo de edición sinóptica deseñado polo filólogo francés. O que esta circunstancia implica é que, cando os principios ensaiados por Roudil se aplican a textos doutra natureza, estes deban adaptarse para que poidan recoller de modo válido a realidade desta nova tradición.

Porén, a lírica profana galego-portuguesa ofrece un conxunto de textos susceptíbeis de seren estudados a partir dunha edición que responda a estes principios teóricos. Un dos factores que adecúan esta tradición poética á realización dunha edición sinóptica é a súa propia realidade material, pois o limitado número de testemuños que nos chegou facilita que poida ser editada no seu conxunto en liñas confrontadas. Outro factor polo que o corpus lírico é máis propenso que outros a ser editado con estes criterios é a súa relativa homoxeneidade, pois as escasas diverxencias significativas dentro da tradición textual facilitan a xustaposición de variantes, facendo destas elementos de gran relevancia debido, precisamente, ao seu número reducido.

\section{UNHA NECESARIA REVISIÓN DA EDICIÓN SINÓPTICA EXPERIMENTAL}

Deseñar unha nova tipoloxía ecdótica é unha empresa titánica que Roudil levou a cabo coa rigorosidade que emana dunha longa traxectoria dedicada á investigación humanística. Porén, e sen desconsiderar o gran labor por el realizado, detectamos certos aspectos conflitivos ao pretender verter a súa proposta metodolóxica á lírica galego-portuguesa. Constatamos, pois, que a revisión dalgúns dos criterios ecdóticos utilizados por Roudil sería un primeiro paso necesario para facer da metodoloxía que sustenta unha edición sinóptica un principio teórico aplicábel a diversas tradicións manuscritas, sen importar o 
xénero ou a súa complexidade, e que permitise realizar con efectividade eses múltiples estudos «experimentais» a que Roudil facía referencia na súa exposición teórica (Roudil 1986: 84).

En primeiro lugar, consideramos que se deben someter a exame os criterios de transcrición empregados no modelo analizado. Aínda que Roudil no seu estudo declara que os manuscritos serán transcritos «très minutieusement et très fidèlement» (1986: 84), nos propios criterios de edición encontrámonos con elementos que representarán graficamente as intervencións editoriais. Porén, descoñecemos cal é a motivación que hai por detrás das modificacións operadas polo editor, pois, en certa medida, van en contra da declaración de principios exposta na propia definición da edición sinóptica: respectar a personalidade de cada un dos testemuños (1986: 81). Non en van, e ao noso modo de ver, este respecto implica reproducir fidedignamente a lección orixinal, mantendo os erros de copia, por evidentes que estes foren, e non incluír correccións, adicións ou interpretacións editoriais.

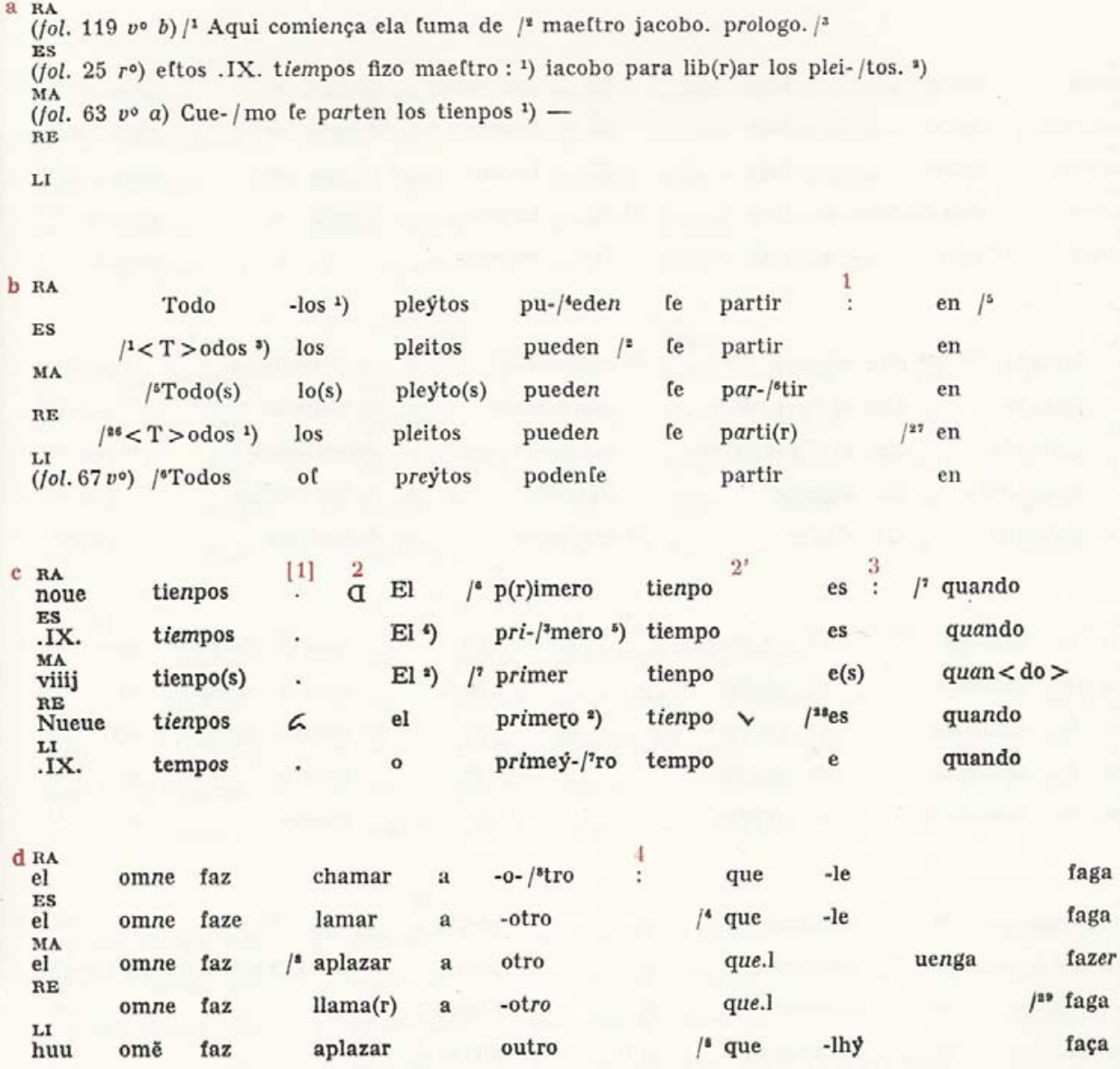

Fig. 1. Fonte: Roudil (1986: 95), Summa de los nueve tiempos de los pleitos. 
A minuciosidade que Roudil anuncia na súa exposición teórica é constatada ao reflectir na súa transcrición determinados alógrafos. Aínda que somos conscientes de que é unha práctica asentada na tradición da investigación humanística, non consideramos que se trate dun criterio coherente a decisión de transcribir certos alógrafos -como a diferenza entre $\langle\mathrm{d}\rangle$ recto e uncial ou entre 〈S〉 longo e curto-, pero que despois non se plasme coa mesma fidelidade as formas materias que adquiren outras letras. A abstracción que vai parella a toda edición, excepto á facsimilar, debe aplicarse de maneira sistemática e coherente, sendo fundamental que o primeiro criterio de toda transcrición implique a diferenciación entre «letra» e «forma da letra».

Facémonos eco, tamén, da valorización que Sánchez-Prieto Borja (1998: 35) realiza desta tipoloxía editorial cando afirma que «la mera superposición de las variantes no puede suplir un aparato crítico». Se ben é certo que a confrontación de variantes é informativa en si mesma, e que a rigorosa e completa análise lingüística que realiza o filólogo francés culmina perfectamente o seu estudo (Roudil 1986: 177 e ss.), botamos en falta a contextualización e o significado de cada unha das variantes. Esta ausencia dunha necesaria contextualización faise máis manifesta, se cabe, coa presenza da que consideramos outra das carencias do estudo de Roudil: a ausencia dunha análise moito máis pormenorizada da transmisión manuscrita dos testemuños editados.

\subsection{Unha nova proposta metodolóxica}

Tras examinarmos criticamente o modelo de edición sinóptica experimental elaborado por Roudil, procedemos a realizar a nosa propia proposta tentando ofrecer propostas alternativas para os problemas detectados no citado modelo.

Só despois de facer un rigoroso estudo da realidade material dos testemuños, xunto cunha profunda análise da transmisión manuscrita, podemos iniciar a transcrición dos textos. É fundamental que esta transcrición paleográfica -ou semidiplomática, para sermos máis precisos- siga uns criterios metodolóxicos actualizados (vid. Sánchez-Prieto Borja 2011); deste modo, podemos realizar unha modesta contribución que axude a cubrir o enorme baleiro existente a día de hoxe no campo editorial da lírica galego-portuguesa. Téñase en conta que do Cancioneiro da Biblioteca Nacional apenas existe unha transcrición paleográfica parcial, datada en 1880 , que debe ser completada e revisada na súa totalidade $^{44}$ e o mesmo podemos afirmar respecto ao Cancioneiro da Biblioteca Vaticana.

\footnotetext{
44 Referímonos á edición de Molteni (1880) en que apenas transcribe aquelas cantigas non presentes no Cancioneiro da Biblioteca Vaticana $(V)$, coa finalidade de completar a transcrición que cinco anos antes realizara Monaci dese cancioneiro (cfr. Monaci 1875). Esta transcrición completaríase, anos despois, cun elenco das variantes rexistradas nas partes comúns a $B$ e $V$ preparado por J. Ruggieri (1927).
} 
Tal e como se indicou en relación aos alicerces teóricos que fundamentan unha edición sinóptica experimental, en particular no que atinxe á elaboración dos criterios que se deben seguir nesta, debemos ter presente a obriga de combinar en todo momento a fidelidade aos testemuños editados con estratexias de organización e disposición do texto que faciliten a análise da variación.

Nese sentido, no que respecta aos criterios de transcrición, as únicas interpretacións editoriais que consideramos pertinentes na reprodución dos testemuños son as referidas á aglutinación ou deglutinación en unidades léxicas e ao desenvolvemento das abreviaturas; intervencións que consideramos necesarias para facilitar o confronto de formas, mais que son diferenciadas graficamente. Se ben é certo, como indica Ramón Lorenzo, que no tocante ás abreviaturas é «de pouca utilidade colocar en itálico as letras desenvolvidas cando só hai unha única posibilidade de lectura» (Lorenzo 2004: 451), consideramos que nun estudo lingüístico debe ficar sempre patente que parte do texto editado se encontraba realmente no testemuño e cal é produto da intervención do editor/a, embora haxa casos en que apenas exista unha lectura posíbel. Do mesmo xeito, propomos o uso do trazo 〈-> coa finalidade de separar as unidades léxicas, criterio que tomamos directamente de Roudil (1986: 85). Cando este elemento precede a un lexema, significa que este estaba aglutinado á unidade anterior, mais, pola contra, un trazo no interior dunha palabra implica que os elementos anteriores e posteriores ao trazo estaban separados no manuscrito. Desta maneira estamos informando da distribución orixinal do texto e, ao mesmo tempo, facilitamos o confronto das formas ${ }^{\text {(vid. Fig 1. e Fig. 2) } 45}$

Un dos criterios de Roudil cuxa modificación resulta máis evidente debido á diferente natureza dos textos editados polo autor francés e os que manexamos para o noso estudo afecta á xerarquía da organización tabular da edición, máis concretamente, á cantidade de texto reproducido en cada unha das liñas obxecto de cotexo e análise. Na poesía, a métrica -alén da súa significación literariaachega valiosísima información non só de corte lingüístico, senón que é imprescindíbel para poder interpretar correctamente moitos dos aspectos ligados ao acto da copia, polo que, no mínimo, o cambio de xénero suporía a presenza dun novo criterio que respectase o fluxo do texto e a disposición deste en versos

Non obstante, cremos que o novidoso da nosa proposta recae na introdución dun novo criterio que implique a identificación, categorización, computación e análise das variantes. A partir dunha división tipolóxica ampla que inclúe catro categorías xenéricas (variantes gráficas, erros de copia, leccións equipolentes e variantes de lingua), procederemos a elaborar un catálogo con subdivisións máis

\footnotetext{
${ }^{45}$ Respectar a unión ou separación de palabras presentes no testemuño achega valiosa información a respecto da «conciencia filológica» (Sánchez-Prieto Borja 1998: 99) dos copistas no que se refire á súa concepción de palabra; desde o punto de vista lingüístico, este respecto da disposición do texto no manuscrito permite advertir, por exemplo, do proceso de gramaticalización de determinados sintagmas.
} 
específicas que, en certa medida, permitirá suplir a falta de contextualización que percibimos na proposta de Roudil coa súa mera superposición de variantes.

De facermos unha edición dixital, soporte co que maior rendemento se tirará a este tipo de edición, a linguaxe de marcado é sen dúbida a ferramenta máis eficaz para codificar o texto, pois permite incorporar as etiquetas que conterían a información adicional acerca da variación textual. ${ }^{46}$ Grazas á introdución de marcas, pódese categorizar sistematicamente a complexa fenomenoloxía da variación textual, alén de, posteriormente, rastrexar no corpus calquera tipo de variación de maneira eficiente, debido ao motor de busca que é posíbel habilitar utilizando este soporte.

Se, pola contra, optamos por unha edición en papel, a marcación dixital ten que ser substituída por un código que, combinando números, cores e letras, permita identificar as variantes, que despois serán explicadas e computadas no final de cada cantiga. Tomando como modelo a edición de Roudil, utilizariamos o espazo e o formato que el emprega para sinalar e comentar os diferentes signos de puntuación para introducir un código de identificación de variantes (vid. números en vermello na Fig. 1, cfr. Fig. 2).

Nesta versión aplícanse algunhas das estratexias empregadas por Roudil (1986) para a distribución do texto, como a división da edición en bloques identificados por unha letra minúscula en vermello, de forma seriada con ordenación alfabética. Cada bloque ofrece a transcrición de todos os manuscritos en que a cantiga estiver presente en liñas horizontais confrontadas, identificadas coa sigla do testemuño no seu inicio (no caso proposto como exemplo na Fig. 2, apenas $A$ e $B$ ). Ademais, o texto contido en cada bloque correspóndese coa transcrición de dous versos, así que en lugar de ofrecer a súa numeración (inferíbel pola letra do bloque), indícase a localización no manuscrito do texto correspondente á transcrición. Para isto, no inicio de cada cantiga sinálase o folio, a columna e a liña en que esta comeza, para despois seguir indicando cada cambio de liña cunha barra oblicua á dereita da cal se indica o número de liña en formato de superíndice; ${ }^{47}$ unha barra oblicua cara á esquerda infórmanos do cambio de columna (como se pode observar na Fig. 2, vid. bloque b, transcrición de $A$ ).

\footnotetext{
${ }^{46}$ Unha linguaxe de marcas ou de marcado é un método de representación dixital a través do cal podemos crear modelos altamente complexos de artefactos textuais. O marcado constitúe unha estrutura informativa que formaliza, etiqueta e «supera» a fonte material: fai explícita a natureza e a función de cada trecho de información, e grazas a esa explicitidade, fai posíbel que procesadores non humanos (como os computadores) poidan «comprender» e utilizar o resto do obxecto dixital de maneiras que aproveiten o seu autocoñecemento sobre a súa estrutura e contido (Flanders 2011: 68).

${ }^{47}$ Aínda que no exemplo da Fig. 2 non hai ningún caso co que ilustrar esa conxuntura, marcaríase con dúas barras oblicuas o cambio de folio.
} 


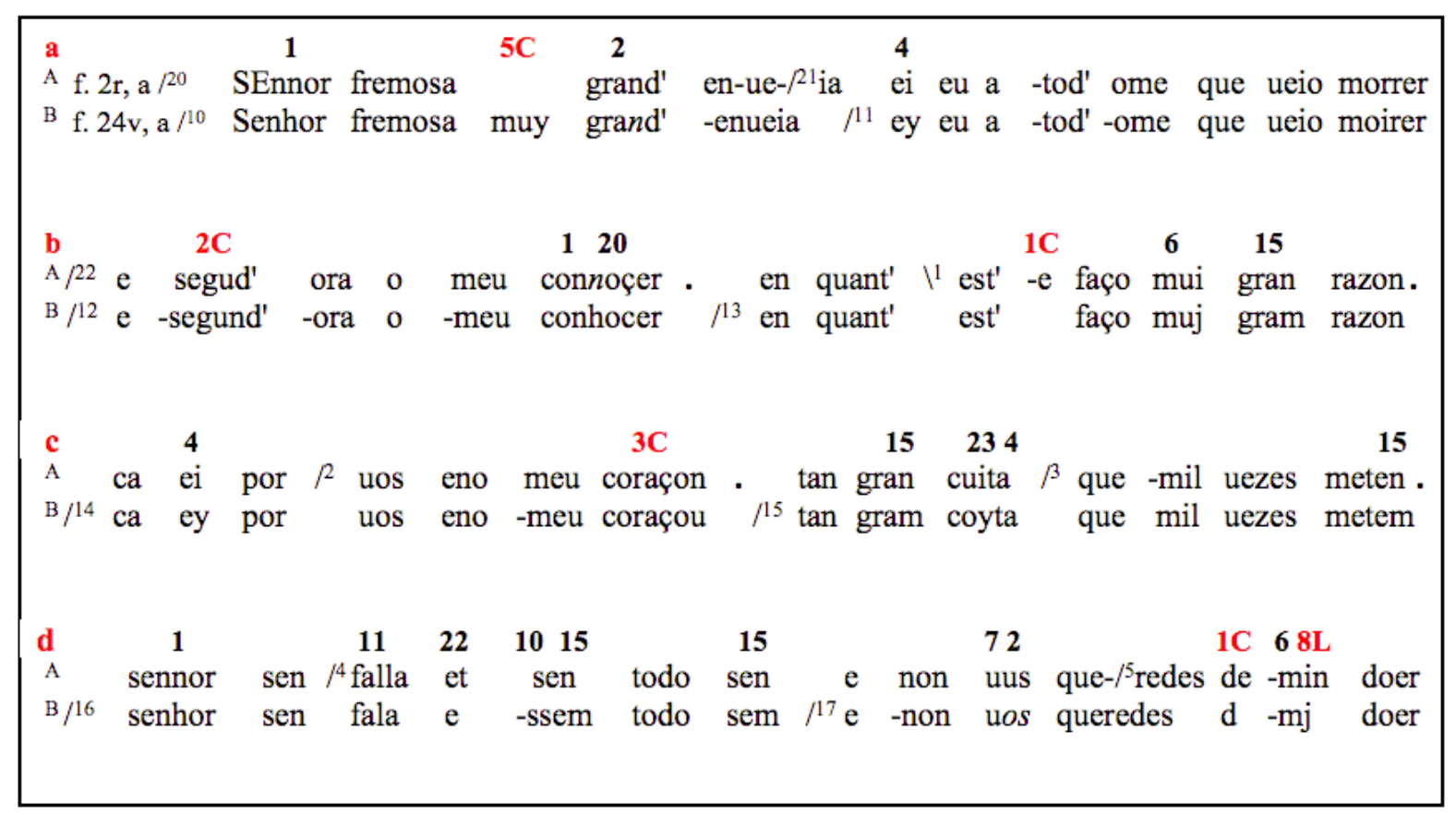

Fig. 2. Exemplo de edición sinóptica correspondente á primeira cobra da cantiga $A 2, B 92$. Fonte: elaboración propia.

Como xa se dixo, utilízase a parte superior de cada bloque para colocar o código alfanumérico que identifica as variacións sinalando as formas afectadas. Se se tratar dunha variante non significativa, é dicir, se esta variación for puramente gráfica, o número é de cor negra. As variantes significativas están enumeradas en vermello, diferenciando as leccións equipolentes, identificadas coa letra $\mathbf{E}$ precedida do número que a individualiza; as variantes de lingua, que se diferencian coa letra $\mathbf{L}$; e os erros de copia, que recoñecidos polo uso da letra C. Evidentemente, este código remite para un índice de correspondencias.

Na Fig. 2, por exemplo, a variante que se corresponde co número 15 indica a utilización do copista de $B$ dun $\langle\mathrm{m}\rangle$ para representar a nasal final en canto $A$ utiliza 〈n〉, e a número 4 infórmanos de que o manuscrito italiano usa 〈y〉 para a representación de /i/ mentres $A$ se decanta por 〈i〉. Do mesmo xeito, 5C marca un erro de copia en $B$ por adición e $\mathbf{1 C}$ un erro por omisión no mesmo testemuño. No tocante á variación lingüística, nese treito temos un único exemplo identificado co código 8L: unha nasalización progresiva en $A$.

Aínda que en ambos os dous soportes a codificación levada a cabo polo editor/a permite que se poidan facer pesquisas de maneira eficaz -sexa cal for a finalidade do noso estudo sobre a tradición manuscrita- a explotación máis frutífera do corpus lírico só podería levarse a cabo a través dunha edición dixital. De facto, non se debería descartar que a escasa traxectoria da edición sinóptica experimental estea relacionada cos inconvenientes que presenta o soporte en papel: a estrutura tabular da edición implica a necesidade dun maior 
espazo e, debido á cantidade de información que achega, faise necesaria a utilización de como mínimo dúas cores na súa impresión para poder xerarquizar os datos que figuran na mesma. Pola contra, as vantaxes do soporte electrónico son múltiples, especialmente se utilizamos unha metodoloxía baseada na codificación do texto facendo uso da linguaxe de marcación XML. ${ }^{48}$

Unha vez escollido este tipo de soporte informático, aconsellamos adherirse a un protocolo de marcado xa establecido e así facilitar o intercambio da información. Debido a que se trata dun proxecto consolidado, en continua revisión e ampliación, ao mesmo tempo que presenta un gran flexibilidade que permite adecuarse de maneira excepcional á maioría dos proxectos de investigación en humanidades, recomendamos o protocolo creado pola Text Encoding Initiative (TEI). ${ }^{49}$

Como se pode observar no seguinte exemplo (vid. Fig. 3), utilizamos o modelo de segmentación en paralelo proposto en TEI (2013b). Cada vez que nos encontramos unha variante, ábrese un sistema de etiquetas que permiten codificar a variación identificando a lectura de cada un dos testemuños. En contraposición, o texto en común (vid. no exemplo Fig. 3 o verso 2, identificado por $<\mathbf{l} \mathbf{n}=$ “2” $>$ ) non presenta marcas especiais.

$\mathrm{O}$ código de identificación de variantes introducido neste caso grazas ao atributo@ana presente dentro de, como mínimo, unha das leccións diverxentes. Coa fin de evitar unha explicación centrada en tecnicismos relacionados co marcado XML/TEI, poremos un exemplo que sirva para ilustrar o funcionamento deste marcado.

Cada unha das etiquetas incluídas dentro do atributo @ana remiten para unha biblioteca de valores. Cada un destes valores está formado, á súa vez, por diferentes trazos, para os cales tamén se dispón dun inventario.

No v. 3 encontramos a referencia "gly", que aparece descrita na nosa biblioteca de valores como:

$<$ fs xml:id="gly" feats="\#glyph \#omiss \#error"/>

A información que aparece recollida dentro de "\#glyph \#omiss \#error", consiste na descrición da variante marcada a través deses tres trazos. Neste caso,

\footnotetext{
${ }^{48}$ A respecto da extensibilidade, lexibilidade, compatibilidade e outras vantaxes de XML sobre outras linguaxes de marcas, recomendamos a lectura de «A Gentle Introduction to XML» (TEI 2013a).

${ }^{49}$ A Text Encoding Initiative (TEI) é un consorcio internacional dedicado a manter as directrices coñecidas como TEI Guidelines, o estándar do que falamos. A TEI desenvolveuse pola necesidade de crear un estándar internacional para a marcación textual que resultou nun congreso en Vassar College, Estados Unidos, en novembro de 1987. Os e as participantes, que representaban diversos repositorios, comunidades científicas, proxectos de investigación e institucións académicas, analizaron neste congreso os diferentes métodos de codificación textual existentes, debateron sobre a viabilidade dun estándar internacional para este tipo de marcado e achegaron recomendacións sobre a súa estrutura, obxectivos, contido, etc. (Cummings 2007: 451). A día de hoxe, o protocolo TEI é utilizado en numerosos proxectos de marcación, especialmente no ámbito das Artes e Humanidades. Ademais, como TEI existiu antes da World Wide Web, as súas recomendacións tamén influíron no desenvolvemento de numerosos estándares web, nomeadamente XML e outros estándares relacionados con este.
} 
CAstro, O. / M. GARCía LiÑEIRA (eds.) (2015): Trama e urda. Contribucións multidisciplinares desde os estudos galegos, Santiago de Compostela, Consello da Cultura Galega. doi:10.17075/tucmeg.2015.

defínese a variante como un erro de copia, por omisión, e que a súa vez se trata da omisión dun signo de abreviatura.

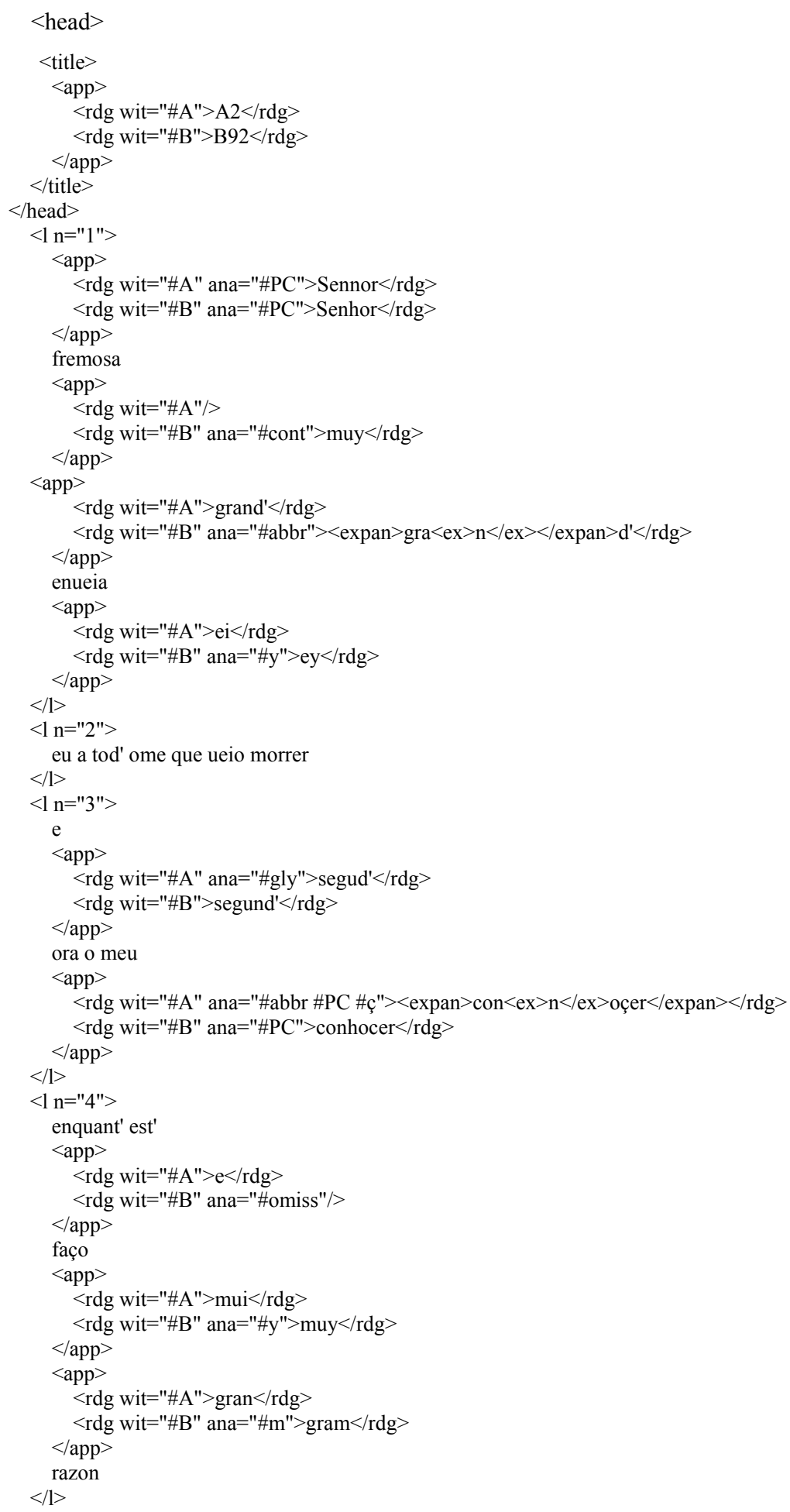

Fig. 3. Exemplo de edición en XML correspondente aos primeiros catro versos da cantiga A2,B92. Fonte: elaboración propia. 
Este sistema permite unha ordenación dos fenómenos de variación moi eficaz, pois podemos ser moi minuciosas na descrición dos mesmos, xa que se poden acrecentar todos os trazos que desexemos. Isto fai que a extracción de datos posterior poida ser tan detallada e precisa como o usuario/a desexar, xa que cada un dos trazos diferenciados pode converterse nun dos filtros de pesquisa.

\subsection{Xustificación desta tipoloxía ecdótica}

Como xa se comentou en parágrafos precedentes, a edición sinóptica nace coa vontade de presentarse como unha ferramenta de análise para que os investigadores/as «experimenten» con ela. Concretamente, a súa aplicación á lírica profana galego-portuguesa suporía, como primeira tarefa, a realización dunha transcrición paleográfica en soporte dixital de todos os testemuños, polo que se supliría unha carencia aínda hoxe demasiado notábel no campo editorial galego-portugués.

Con todo o corpus textual correctamente marcado, as posibilidades son innumerábeis. Por unha banda, este traballo permitiría a descrición dos distintos sistemas gráficos e descodificaría as posíbeis normas gráficas presentes nos relatores. Cunha edición deste tipo, en que son detectadas todas as variantes gráficas, temos unha base moi completa para realizar unha completa análise grafemática que faría posíbel identificar fenómenos de variación lingüística e, ao mesmo tempo, precisar certos elementos da xénese dos manuscritos analizados, como poden ser a detección de substratos gráficos, a localización da orixe dos copistas e a identificación de determinadas fontes.

Ademais, a propia estrutura tabular da edición, xunto coa incorporación das catro categorías xenéricas que encadran o fenómeno da variación -variantes gráficas, erros de copia, leccións equipolentes e variantes de lingua- convértese, como xa se sinalou, nunha ferramenta útil para empregar como base dunha edición crítica, xa que facilita os procesos de elaboración desta, especialmente os referidos á collatio codicum.

Unha vez detectadas todas as variantes de lingua coa súa correspondente categorización, dispomos dun corpus de exemplos que permitirán realizar estudos de tipo analítico que versen sobre os propios fenómenos de variación, abordando os planos fonético-fonolóxico, morfolóxico, sintáctico e, incluso, semántico. Ao mesmo tempo, a realización dun estudo descritivo que conteña estes datos permitirá expor as principais características da gramática galegoportuguesa na época que nos atinxe, exemplificando co valioso corpus textual da lírica galego-portuguesa e describindo, desde o punto de vista da lingua, os diferentes testemuños, feito que achegará máis información sobre a propia transmisión manuscrita. 


\section{VALORACIÓNS FINAIS}

A edición sinóptica, entendida como unha «edición múltiple para el estudio lingüístico» (Orduna 1986: 105), presenta unha serie de facilidades metodolóxicas das cales carecen outro tipo de edicións. Porén, o estudo lingüístico non pode ser abordado sen coñecer as condicións de produción e transmisión dos testemuños que se analizan, pois só así podemos interpretar a información que nos ofrece este tipo de edición.

Partindo destas premisas, algúns dos criterios utilizados por Roudil, creador desta tipoloxía ecdótica, deben ser modificados de querer aplicarse á lírica profana galego-portuguesa para o estudo da variación lingüística que nesta se verifica. Esta modificación obedece, en parte, ás diverxencias dos textos obxecto de estudo, pero tamén deben incluírse outro tipo de correccións motivadas pola falta de contextualización que percibimos na edición de Roudil e á ausencia dun estudo máis sistematizado da variación.

Como valoración final, queremos insistir na dimensión experimental desta tipoloxía ecdótica. Por unha banda, debemos pór énfase no valor que elaborar unha edición deste tipo suporía para os estudos que versen sobre a lírica profana galego-portuguesa no que atinxe á mera transcrición dos códices, pois, como xa se dixo, existe unha importantísima lacuna no campo editorial galego e portugués no que se refire ás edicións paleográficas. Así, unha edición sinóptica experimental permitiría que este corpus puidese ser empregado como fonte para diversos estudos, e, en particular - debido ao seu interese- para aquelas achegas que busquen confrontar a lingua trobadoresca cos diferentes modelos escriturais e lingüísticos que funcionaron durante o século XIII e inicios do XIV no espazo centro-occidental ibérico. Abriríase deste xeito unha interesante liña de investigación que se marcaría como obxectivo explicar o desenvolvemento interno e externo deste movemento poético, que, ao mesmo tempo, pode utilizarse como unha das fontes para un estudo histórico-social das dinámicas culturais (e socio-políticas) imperantes dentro das coordenadas espazotemporais en que se produce este movemento literario.

Alén do máis, categorizar e ordenar o fenómeno da variación dunha maneira pormenorizada e rigorosa, excedendo o campo do estritamente lingüístico (tal e como propomos) implica que, ademais de como fonte para estudos de gramática histórica, este corpus poida servir como base para outros tipos de edición, facilitando todos os pasos previos á constitutio textus. Así pois, unha edición sinóptica experimental pode ser rendibilizada desde distintos campos da investigación filolóxica, mostrando as vantaxes que xorden da conservación das particularidades dos diferentes testemuños escritos que transmiten unha obra e do seu confronto. En palabras de Jean Roudil: «une tradition manuscrite, toutes proportions gardées, était le magnétophone du médiéviste puisqu'elle nous livre 
CAstro, O. / M. García LiñeIRA (eds.) (2015): Trama e urda. Contribucións multidisciplinares desde os estudos galegos, Santiago de Compostela, Consello da Cultura Galega. doi:10.17075/tucmeg.2015.

de multiples réalisations $\mathrm{d}$ un texte, qui sont nos précieux disques $\mathrm{d}$ or, informateurs des possibilités $d$ expression $d$ un moment, d'une époque, d'époques et constitutifs d un matériau linguistique de première importance»» (1986: 90).

\section{REFERENCIAS BIBLIOGRÁFICAS}

ARBOR, Mariña (2004): «Il Cancioneiro da Ajuda prima di Carolina Michaëlis (1904)», Critica del testo, 7(2), 721-789.

ARBOR, Mariña (2008): Cancioneiro da Ajuda, Santiago de Compostela, Xunta de Galicia.

ARBOR, Mariña (2009). «Un códice de historia material compleja: El Cancioneiro da Ajuda», Revista Medieval, 21, 77-124.

ARBOR, Mariña / Xavier VARELA (2008): «O uso dos signos gráficos $<\mathrm{i}>$ e $<\mathrm{y}>$ como segundo elemento de ditongo decrecente. A evidencia de dúas mans na copia do Cancioneiro da Ajuda», en Mercedes Brea (coord.), Cada palabra pesaba, cada palabra media. Homenaxe a Antón Santamarina, Santiago de Compostela, Universidade, 419-442.

Cancioneiro da Biblioteca Nacional (Colocci-Brancutti). Cod. 10991, Lisboa, Biblioteca Nacional, 1982.

CUMMINGS, James (2007): «The Text Encoding Initiative and the Study of Literature», en Raymond Siemens / Susan Schreibman (eds.), A Companion to Digital Literary Studies, Malden, Blackwell, 451-476.

FERRARI, Anna (1979): «Formazione e struttura del Canzoniere Portoghese della Biblioteca Nazionale di Lisbona (Cod. 10991: Colocci-Brancuti). Premesse codicologiche alla critica del testo (Materiali e note problematiche)», Arquivos do Centro Cultural Português, XIV, 27-142.

FERRARI, Anna (1993a): s.v. «Cancioneiro da Biblioteca Nacional (Colocci-Brancuti)», en Giulia Lanciani / Giuseppe Tavani (coords.), Diccionário da Literatura Medieval Galega e Portuguesa, Lisboa, Caminho (= DLMGP), 119-122.

FERRARI, Anna (1993b): s.v. «Cancioneiro da Biblioteca Vaticana», en DLMGP, 123-126.

FERREIRO, Manuel (2008a): «Edición e historia da lingua: sobre a representación da nasalidade no trobadorismo profano galego-portugués e as formas "irmana" e afíns», en Manuel Ferreiro (coord.), A edición da poesía trobadoresca en Galiza, A Coruña, Baía, 77-96.

FERREIRO, Manuel (2008b): «A forma verbal "éste" na lírica profana galego-portuguesa», Revista Galega de Filoloxía, 9, 57-78.

FLANDERS, Julia (2011): «Collaboration and Dissent: Challenges of Collaborative Standards for Digital Humanities», en Marilyn Deegan / Willard McCarthy (eds.), Collaborative research in Digital Humanities, Surrey, Ashgate, 67-80.

Fragmento do Nobiliário do Conde Dom Pedro. Cancioneiro da Ajuda. Edição fac-similada do códice existente na Biblioteca da Ajuda, Lisboa, Edições Távola Redonda, 1994.

GONÇALVES, Elsa (1993): s.v. «Tradição manuscrita da poesia lírica», en DLMGP, 627632. 
CAstro, O. / M. García LiñeIRA (eds.) (2015): Trama e urda. Contribucións multidisciplinares desde os estudos galegos, Santiago de Compostela, Consello da Cultura Galega. doi:10.17075/tucmeg.2015.

LANCIANI, Giulia / Giuseppe TAVANI (coords.) (1993): Diccionário da Literatura Medieval Galega e Portuguesa, Lisboa, Caminho (= DLMGP).

LORENZO, Ramón (2004): «Edición de documentos medievais. Problemas que presentan algunhas abreviaturas», en Rosario Álvarez (coord.), (Dis)cursos da escrita. Estudos de filoloxía galega ofrecidos en memoria de Fernando $R$. Tato Plaza, A Coruña, Fundación Pedro Barrié de la Maza, 449-458.

MARIÑO, Ramón / Xavier VARELA (2005): «O uso dos signos gráficos $<\mathrm{u}>,<\mathrm{V}>\mathrm{e}<\mathrm{U}>$ no Cancioneiro da Ajuda», en Mercedes Brea (coord.), Carolina Michaëlis e o Cancioneiro da Ajuda, hoxe, Santiago de Compostela, Xunta de Galicia, 309-374.

MOLTENI, Enrico (ed.) (1880): Il Canzoniere portoghese Colocci-Brancuti, Halle, M. Niemeyer.

MONACI, Ernesto (ed.) (1875): Il Canzoniere portoghese della Biblioteca Vaticana, Halle, M. Niemeyer.

ORDUNA, Germán (1986): «Un nuevo tipo de edición: "la edición sinóptica experimental"», Incipit, VI, 103-105.

ORDUNA, Germán (2005): «La edición de textos históricos en español (Estado actual del tema, estudios e investigaciones a realizar)», en Fundamentos de crítica textual, Madrid, Arco Libros, 149-160.

PÉREZ PRIEGO, Miguel Ángel (1997): La edición de textos, Madrid, Síntesis.

RAMOS, Maria Ana (1988): «Um provençalismo no Cancioneiro da Ajuda: "senner"», en Dieter Kremer (ed.), Homenagem a Joseph M. Piel por ocasião do seu $85^{\circ}$ aniversário, Tübingen, Max Niemeyer, 622-637.

RAMOS, Maria Ana (1993): s.v. «Cancioneiro da Ajuda», en DLMGP, 115-117.

RAMOS, Maria Ana (1994): «Descrição do manuscrito», en Apresentação, estudos e índices. Fragmento do Nobiliário do Conde Dom Pedro. Cancioneiro da Ajuda. Edição facsimilada do códice existente na Biblioteca da Ajuda, Lisboa, Távola Redonda, 27-47.

RAMOS, Maria Ana (2005): «Letras perfeytas? Grafias entre manuscritos e impressos», en P. Botta (ed.), Filologia dei Testi a Stampa (area iberica), Modena, Mucchi Editore, 381-405.

RAMOS, Maria Ana (2009): «La genesi di un canzoniere: copisti e dinamica testuale», en Furio Brugnolo (ed.), La lirica romanza del Medioevo. Storia, tradizioni, interpretazioni, Padova, Unipress, II, 473-492.

RAMOS, Maria Ana (2011): “"Sombras” grafemáticas. Dimensão diacrónica na formação dos cancioneiros galego-portugueses», en L. Leonardi (ed.), La tradizione della lirica nel medioevo romanzo. Problemi di filologia formale, Firenze, Edizioni del Galuzzo per la Fondazione Ezio Franceschini, 333-361.

RODRÍGUEZ GUERRA, Alexandre / Xavier VARELA (2007): «As grafías no Cancioneiro da Ajuda», en Ana Isabel Boullón Agrelo (coord.), «Na nosa lyngoage galega». A emerxencia do galego como lingua escrita na Idade Media, Santiago de Compostela, Consello da Cultura Galega, 473-556.

ROUDIL, Jean (1986): Summa de los nueve tiempos de los pleitos. Édition et étude d'une variation sur un thème par Jean Roudil, Paris, Klincksieck.

RUGGIERI, Jole (1927): «Le varianti del canzoniere portoghese Colocci Brancuti nelle parti comuni al Codice Vaticano 4803», Archivum Romanicum, 9, 459-510.

SÁNCHEZ-PRIETO BORJA, Pedro (1998): Cómo editar los textos medievales. Criterios para su presentación gráfica, Madrid, Arco Libros. 
CAstro, O. / M. GARCía LiÑEIRA (eds.) (2015): Trama e urda. Contribucións multidisciplinares desde os estudos galegos, Santiago de Compostela, Consello da Cultura Galega. doi:10.17075/tucmeg.2015.

SÁNCHEZ-PRIETO BORJA, Pedro (2011): La edición de textos españoles medievales y clásicos. Criterios de presentación gráfica [Documentos de CHARTA y textos literarios], San Millán de la Cogolla, Cilengua.

SOUTO CABO, José António (2008): «O texto das cantigas nas práticas escriturais do sec. XIII», en Manuel Ferreiro (ed.), A edición da poesía trovadoresca en Galiza, A Coruña, Baía, 161-176.

TEI CONSORTIUM (ed.) (2013a): «A Gentle Introduction to XML», en TEI Consortium (ed.), TEI P5: Guidelines for Electronic Text Encoding and Interchange, 2.5.0., actualización do 26/07/2013, (http://www.tei-c.org/release/doc/tei-p5doc/en/html/SG.html) [última consulta: 15/09/2013].

TEI CONSORTIUM (2013b): «The Parallel Segmentation Method», en TEI Consortium (ed.), TEI P5: Guidelines for Electronic Text Encoding and Interchange, 2.5.0., actualización do 26/07/2013. (http://www.tei-c.org/release/doc/tei-p5doc/en/html/TC.html\#TCAPPS) [última consulta: 15/09/2013].

VARELA, Xavier (2005): «Os usos das letras maiúsculas no Cancioneiro da Ajuda», en Ana Isabel Boullón Agrelo (coord.), As tebras alumeadas. Estudos filolóxicos ofrecidos en homenaxe a Ramón Lorenzo, Santiago de Compostela, Universidade de Santiago de Compostela, 275-288.

ZUFFEREY, François (1987): Recherches linguistiques sur les chansonniers provençaux, Genève, Librairie Droz 